\title{
Influence of Ionic Strength on the pH-sensitive in vitro Ibuprofen Release from Dextran-poly(acrylic acid) Copolymer
}

\author{
YANNA ZHANG, JIHONG SUN, XIAOQI JIN AND XIE WU \\ Beijing Key Laboratory for Green Catalysis and Separation, Department of Chemistry and Chemical Engineering, Beijing \\ University of Technology, Beijing 100124, P. R. China
}

\section{Zhang, et al.: Influence of Ionic Strength on Ibuprofen Release}

\begin{abstract}
The effects of cations and $\mathrm{pH}$ on the in vitro ibuprofen release from dextran-poly(acrylic acid) copolymer were investigated at varying $\mathrm{pH}$ and $\mathrm{Na}^{+}$or $\mathrm{Ca}^{2+}$ concentrations. These results revealed that ibuprofen release was strongly depended on the acidic and basic environments, in which, the cumulative amount released in $24 \mathrm{~h}$ reached up to $87 \%$ at pH 2.0 but only $32 \%$ at pH 7.4, respectively, demonstrating a good pH-dependency. However, cations in release solution exerted a remarkable influence on ibuprofen release, especially in the acidic media. Meanwhile, ibuprofen release rate decreased with increasing strength of $\mathrm{Na}^{+}, \mathrm{Ca}^{2+}$ and $\mathrm{NaCl}$ concentration. The zeta potential profiles and particle distributions at different ionic strengths indicated that cations strongly influence ibuprofen release performance, through surface charge, hydrogen-bonding, and electrostatic interactions in and between the polymer and ibuprofen. These results suggested that $\mathrm{Na}^{+}$and $\mathrm{Ca}^{2+}$ strength exerted a profound influence on the $\mathrm{pH}$-sensitive in vitro ibuprofen release from the dextranpoly(acrylic acid) copolymer.
\end{abstract}

Key words: Dextran-poly(acrylic acid) copolymer, dextran, ibuprofen, pH-sensitivity, salt effect

During the past few decades, new polymer-based acrylic particles have attracted extensive attentions due to its $\mathrm{pH}$-dependent shrinking-swelling behaviours ${ }^{[1]}$. Quintero et al. ${ }^{[2]}$ investigated the swelling behaviour of polyvinyl alcohol (PVA) and polyacrylic acid (PAA) hydrogels in buffer solutions at different $\mathrm{pH}$ values and found that its swelling performance increased with $\mathrm{pH}$ value, evidently demonstrating that PVA, PAA hydrogels were a promising candidate for the $\mathrm{pH}$ sensing drug carrier. Meanwhile, Abd El-Rehim et al. ${ }^{[3]}$ prepared a PAA-based drug carrier with polyvinylpyrrolidone (PVP)/PAA as a template polymer and then investigated its swelling properties and release behaviours. They found that the caffeine release from obtained PVP/PAA copolymer was slower than that from PAA, whereas, the carboxylic groups of PAA in the PVP/PAA polymer led to a lower release rate of caffeine at lower $\mathrm{pH}$. These results clearly indicate that that the copolymers are suitable carriers for drug delivery systems with stimuli responsibility to $\mathrm{pH}$. Since then, numerous preparations and potential applications of the $\mathrm{pH}$ responding swelling/ release behaviours of various copolymers have been extensively explored ${ }^{[4]}$.

*Address for correspondence

E-mail: jhsun@bjut.edu.cn

March-April 2018
The drug-releasing behaviours from stimuliresponsible copolymer are greatly dependent on various interactions caused by aqueous property, copolymer skeleton, and drug structure ${ }^{[5]}$. Based on the variables of the gastrointestinal (GI) fluids ${ }^{[6]}$ in the human body, it has been concluded that the $\mathrm{pH}$ environments and cation charge are two major parameters considered in the design of oral extended release formulations ${ }^{[7]}$. Several investigators have sought to examine the effects of ionic strength on drug-release performances. Lapidus and Lordi early noted this effect and demonstrated rapid release of chlorpheniramine in $0.2 \mathrm{M}$ solutions of sodium and magnesium sulphates from hydroxypropyl methylcellulose type 2208 matrices $^{[8]}$. Mitchel et al. further investigated the effects of various ions and concentrations on the disintegration time and dissolution of drugs from these

This is an open access article distributed under the terms of the Creative Commons Attribution-NonCommercial-ShareAlike 3.0 License, which allows others to remix, tweak, and build upon the work non-commercially, as long as the author is credited and the new creations are licensed under the identical terms

Accepted 02 February 2018

Revised 12 June 2017

Received 28 December 2016

Indian J Pharm Sci 2018;80(2):298-306 
matrices ${ }^{[9]}$. Therefore, numerous studies have been focused on the evaluations of their $\mathrm{pH}$-responsibility and salt effects on these polymers under the abovementioned biological conditions ${ }^{[10]}$. Fu et al.$^{[11]}$ prepared the poly(acrylamide-co-acrylic acid) hydrogels and elucidated the salt effect on swelling ratios. They found that the swelling rate of the hydrogels abruptly declined with the swelling media changed from distilled water to $\mathrm{NaCl}$ solution, indicating the unique property of the polymers. Awasthi and Singhal ${ }^{[12]}$ synthesized a series of poly(acrylamide-co-hydroxyethylacrylamideco-acrylic acid) hydrogels and investigated the effect of $\mathrm{NaCl}$ concentration on swelling behaviours. The experimental results demonstrated that the swelling ratios of all hydrogels apparently decreased with the increase of $\mathrm{NaCl}$ concentration due to the decrement in the expansion of the gel networks. In addition, the equilibrium swelling ratio of the hydrogels in various salt solutions decreased with the increase of cationic charges, following the order of $\mathrm{Na}^{+}>\mathrm{Ca}^{2+}>\mathrm{Fe}^{3+}$.

Our previous work ${ }^{[13]}$ has clearly demonstrated that the vinyl triethoxylsilane-modified polymethylacrylic acid copolymer is a highly $\mathrm{pH}$-sensitive material. However, further investigation found that its swelling-shrinking properties were significantly declined with the increase of $\mathrm{NaCl}$ concentration. All these studies have demonstrated the profound effects of salt solutions on the swelling ratio of the copolymers. However, their influences on the drug-release performance of the copolymers are still vague.

Dextran is a water-soluble polysaccharide ${ }^{[14]}$ and is clinically used in food and medical fields due to its lack of toxicity, biodegradability and biocompatibility ${ }^{[15-17]}$. Dextran-based nanoparticles exhibited a pronounced $\mathrm{pH}$-sensitivity because of the carboxy groups in the nanoparticles ${ }^{[18]}$. Zhang et al. reported a novel $\mathrm{pH}-$ and ionic-strength-sensitive carboxymethyl dextran hydrogel membrane, in which the acidic groups caused the $\mathrm{pH}$-dependent swelling ${ }^{[19]}$. However, pH-sensitive polymer based on dextran has not been used in the drug loading and controlleddelivery ${ }^{[20]}$. More recently, we synthesized a modifiedcopolymer, dextran-poly(acrylic acid) copolymer (D-A copolymer) by grafting a synthetic PAA onto dextran and demonstrated its non-toxicity, biocompatibility, excellent biodegradability, and $\mathrm{pH}$-sensitivity ${ }^{[21]}$. Its drug loading and releasing performance in phosphate buffer solutions (PBS) at pH 2.0 and 7.4 was investigated with ibuprofen (IBU) as model drug. The results show that the prepared copolymer is sensitive to the $\mathrm{pH}$ of its releasing environment, and its $\mathrm{pH}$-sensitivity is increased with the increase of the molar ratio of AA/dextran. However, the influences of salt concentration and species on its drug-release performance are unknown. The present work has been focused on the tolerance of the in vitro drug-release performance of the D-A copolymers to salts using IBU as a model drug. IBU is a well-known nonsteroidal antiinflammatory drug that has been extensively used to treat rheumatoid arthritis and atherosclerosis ${ }^{[22]}$. However, IBU cannot be effectively absorbed due to its relatively poor water-solubility. In addition, its halflife is only 1.5 or $2 \mathrm{~h}$, which requires frequent dosing to maintain effective blood drug concentration ${ }^{[23]}$. Therefore, it is suitable as a model drug to evaluate performance of novel drug delivery systems. The effects of different salt species and concentrations on the zeta potential and particle distribution of D-A copolymer were also investigated in the present work.

\section{MATERIALS AND METHODS}

Dextran, acrylic acid, cerium (IV) ammonium nitrate (CAN), N,N-methylene bisacrylamide (MBA) was obtained from Sinopharm Chemical Reagent Co. Ltd, China. MBA was re-crystallized from methanol before using. Hydrochloric acid $(\mathrm{HCl})$, ammonia solution $\left(\mathrm{NH}_{3} \cdot \mathrm{H}_{2} \mathrm{O}\right)$, sodium chloride $(\mathrm{NaCl})$, sodium hydroxide $(\mathrm{NaOH})$, nitric acid $\left(\mathrm{HNO}_{3}\right)$ and ethanol all of analytical grade were purchased from Beijing Chemical Factory. Analytical grade anhydrous calcium chloride $\left(\mathrm{CaCl}_{2}\right)$ was obtained from Tianjin Fuchen Chemical Reagents Factory. IBU was provided by Zibo Beikang Biotechnology Co. Ltd. PBS was made from disodium hydrogen phosphate, sodium dihydrogen phosphate and phosphoric acid in a particular proportion. Deionized water was used throughout all experiments.

\section{Preparation of dextran-PAA polymer:}

Synthesis of dextran-PAA was based on a reported procedure, originally as described by Guo et al. ${ }^{[21]}$. About $1.25 \mathrm{~g}$ dextran was dissolved in $50 \mathrm{ml}$ deionized water with mild magnetic stirring and nitrogen bubbling, then the solution of a specific amount of CAN dissolved in $1.25 \mathrm{ml}$ dilute $\mathrm{HNO}_{3}(0.1 \mathrm{~mol} / \mathrm{l})$ and ten moles of acrylic acid per mole of dextran Tunit (glucose) were added into the flask. After $0.5 \mathrm{~h}, \mathrm{MBA}$ was added to the reaction mixture and then kept on stirring at $30^{\circ}$ for $4 \mathrm{~h}$. Thereafter, $1 \mathrm{M} \mathrm{NaOH}$ was added to neutralize the reaction system. Finally, the reaction 
solution was precipitated with ethanol to remove the un-reactive monomers. The obtained products were filtered and washed with ethanol for several times and dried at $40^{\circ}$, denoted as D-A.

\section{Drug loading:}

About $0.3 \mathrm{~g}$ D-A was dissolved in $30 \mathrm{ml}$ IBU ethanol solution $(30 \mathrm{mg} / \mathrm{ml})$ containing in a flask and the mixture was stirred using magnetic stirring apparatus for $48 \mathrm{~h}$ at room temperature. Then the solution was filtered and washed with ethanol to remove excess IBU adsorbed on the outer surface of D-A. Finally, the product was dried under vacuum and denoted as I/D-A. To evaluate the amount of drug loaded by D-A copolymer, high-performance liquid chromatography (HPLC) was used for analysis. First of all, the calibration curve of IBU was prepared by measuring absorbance of IBU concentration between 0.1 and $18 \mathrm{mg} / \mathrm{ml}$, and the calibration curve was fitted as follows: $\mathrm{C}=0.0031 \mathrm{~A}+0.0117, R^{2}=0.9999$, where, $\mathrm{A}$ is the peak area and $\mathrm{C}$ is the concentration $(\mathrm{mg} / \mathrm{ml})$.

After adsorption, the IBU solution $(1 \mathrm{ml})$ was extracted and diluted to $50 \mathrm{ml}$, and then analysed using a HPLC (Agilent Technologies 1200 series), set with the following parameters, wavelength was $272 \mathrm{~nm}$, chromatographic column was Extend-C18, and the mobile phase was anhydrous methanol- $\mathrm{pH} 3.0$ phosphate buffer (volume ratio of 3:1), the flow rate was $1.000 \mathrm{ml} / \mathrm{min}$ and injection volume was $6 \mu \mathrm{l}$. The retention time of a characteristic peak in the HPLC of the IBU was $6.6 \mathrm{~min}$. The loading amount (LA) was calculated using the following Eqn., LA (\%) = $\mathrm{m}_{0}-\mathrm{m}_{1} / \mathrm{m}_{2}+\left(\mathrm{m}_{0}-\mathrm{m}_{1}\right) \times 100$, where, $\mathrm{m}_{0}$ is the weight of IBU added initially, $m_{1}$ is the weight of IBU in the filtrate, and $\mathrm{m}_{2}$ is the weight of copolymer D-A. The LA \% was 7.2 through the measurement and calculation.

\section{In vitro drug release:}

Release test of IBU was carried out as follows. The release medium was PBS solution ( $\mathrm{pH}$ value of 2.0 and 7.4), $1.0 \mathrm{M} \mathrm{HCl}$ solution ( $\mathrm{pH} 2.0)$ and $1.2 \mathrm{M} \mathrm{NH}_{3} \cdot \mathrm{H}_{2} \mathrm{O}$ ( $\mathrm{pH}$ 9.3). $\mathrm{CaCl}_{2}$ anhydrous and $\mathrm{NaCl}$ were used to regulate the ionic strength and ionic concentration at $\mathrm{pH} 2.0$ and 9.3. Firstly, samples were pressed into slice $(10 \mathrm{mg})$ and put into dialysis bag with a 14000 cutoff molecular weight, and then immersed into different release mediums $(10 \mathrm{ml})$ at $37^{\circ}$. In the course of the drug release, $1 \mathrm{ml}$ of this solution was taken out at certain time intervals for drug measurement. The total volume of the solution was kept constant by adding $1 \mathrm{ml}$ of the fresh medium after each sampling. The concentration of the drug-released was determined by UV/Vis spectroscopy monitored at $272 \mathrm{~nm}$ because of low concentration of IBU in the release solutions. The calibration curve of IBU was determined by taking absorbance vs. IBU concentration between 0.0005 and $0.5 \mathrm{mg} / \mathrm{ml}$, and the calibration curve was fitted as follows: $\mathrm{C}=0.7012 \mathrm{~A}-0.00329, R^{2}=0.9999$, where $\mathrm{A}$ is the peak area and $\mathrm{C}$ is the concentration $(\mathrm{mg} / \mathrm{ml})$.

All measurements were made two times and standard deviations $\left(R^{2}\right)$ from the average value were more than 0.999. The released drug content was calculated according to the following formula, $\mathrm{C}_{\mathrm{c}}=\mathrm{C}_{\mathrm{t}}+\mathrm{v} / \mathrm{V} \times$ $\sum_{0}^{\mathrm{t}-1} \times \mathrm{C}_{\mathrm{t}}$, where, $\mathrm{C}_{\mathrm{c}}(\mathrm{mg} / \mathrm{ml})$ is the corrected concentration at time $\mathrm{t}(\mathrm{min}), \mathrm{C}_{\mathrm{t}}(\mathrm{mg} / \mathrm{ml})$ is the apparent concentration at time $t(\mathrm{~min}), \mathrm{v}(\mathrm{ml})$ is the volume of sample taken, and V ( $\mathrm{ml})$ is the total volume of the released fluids.

\section{Characterizations:}

Fourier transform infrared spectroscopy (FTIR) spectrum was measured using $\mathrm{KBr}$ discs in the region of $4000-400 \mathrm{~cm}^{-1}$ by a Nicolet Nexus 470 spectrometer to analyse the composition of the resultant copolymer. Thermogravimetric analysis (TGA) were carried out between 25 and $800^{\circ}$ using a Seiko TG/DTA 320 with an $\mathrm{N}_{2}$ flow rate $100 \mathrm{ml} / \mathrm{min}$ and a heating rate of $10 \%$ min. Scan electron microscopy (SEM, Hitachi S-4300, Japan) images were obtained by a Hitachi S-4300 electron microscope at an acceleration voltage of $15 \mathrm{kV}$. Agilent Technologies HPLC-1200 series was used to measure the amount of IBU loaded. A Shimadzu UV-2450 spectrophotometer was used to measure the amount of IBU released from the samples. Zeta-potential was measured by particle sizing systems (Nicomp 380/ZLS) and the particle size distribution of the copolymer was carried out by Zetasizer Nano Series (Nano-ZS) instrument.

\section{RESULTS AND DISCUSSION}

Fig. 1 shows the TGA profiles of dextran and D-A copolymer. As can be seen, both polymers subjected two decomposition stages. The $7 \%$ weight loss at temperatures below $100^{\circ}$ was ascribed to the evaporation of the physically absorbed water, and the $52 \%$ weight loss at temperature range of $250-360^{\circ}$ was assigned to the degradation of their saccharide structure $^{[24]}$. Interestingly, as profiled in fig. $1 \mathrm{~b}$, D-A copolymer subjected an addition decomposition stage in the temperature range of $450-480^{\circ}[25]$, which was attributed to the presence of PAA (fig. 1a vs. b). 
Meanwhile, the surface morphology of D-A copolymer is a thick sheet structure (fig. 1 inset A) and the SEM image with high magnification (fig. 1 inset B) exhibits the highly porous cross-linked networks, which can promote the swelling rate and drug delivery.

In addition, two new absorption peaks at $1419 \mathrm{~cm}^{-1}$ and $1547 \mathrm{~cm}^{-1}$ appeared in the FTIR spectrum of D-A copolymer, which were attributed to asymmetric and symmetric stretching vibrations of carboxyl groups of PAA $^{[26]}$ as compared with that of pure dextran. While the typical C-O-C asymmetrical stretching of dextran at $1152 \mathrm{~cm}^{-1}$ and $1104 \mathrm{~cm}^{-1[27]}$, and $\mathrm{C}-\mathrm{H}$ stretching vibration at $2918 \mathrm{~cm}^{-1}$ were also present in the FTIR spectrum of D-A copolymer. Based on these results, it can be concluded that AA has been successfully grafted to the dextran skeletons.

The drug release tests were conducted by soaking I/D-A copolymer in PBS medium with $\mathrm{pH}$ of $\mathrm{pH} 2.0$ and 7.4 at $37^{\circ}$, as shown in fig. 2 . It can be seen clearly that the IBU-release rate at $\mathrm{pH} 2.0$ was obviously faster than that at $\mathrm{pH}$ 7.4. Accordingly, the cumulative release for D-A copolymer reached up to about $65 \%$ within $2 \mathrm{~h}$ in the $\mathrm{pH} 2.0 \mathrm{PBS}$ solution, while, the released amount was around $34 \%$ of cumulative total within $2 \mathrm{~h}$ in the $\mathrm{pH}$ 7.4 PBS solution. The cumulative release reached 87 and $32 \%$, respectively in $24 \mathrm{~h}$. These phenomena could be explained on the basis of $\mathrm{pH}$ influence on the structures of both D-A copolymer and IBU. The pKa of PAA and IBU are 4.75 and 4.91, respectively ${ }^{[28]}$, and thereafter both PAA and IBU were protonated in the acidic solution ( $\mathrm{pH}$ 2.0). D-A copolymer was in a neutral state and its internal electrostatic repulsion

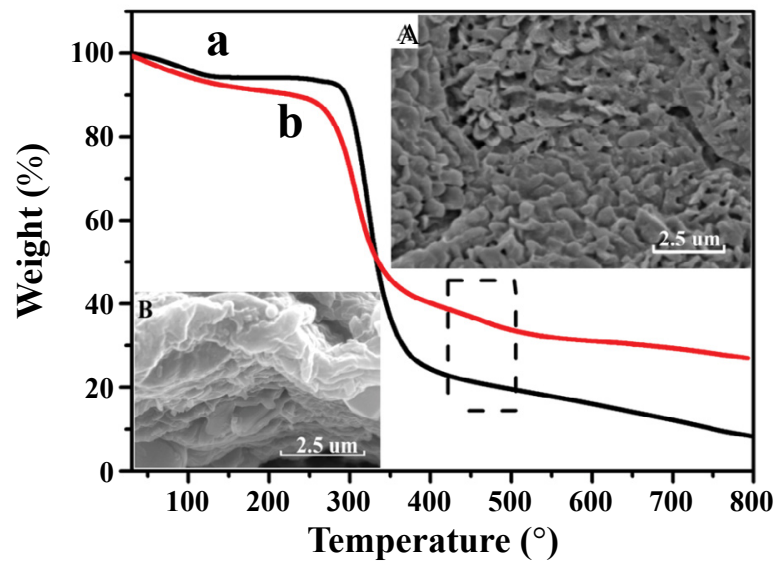

Fig. 1: TGA curves of the dextran and D-A copolymer and the corresponding SEM images

Thermogravimetric (TGA) curves of (a) dextran and (b) D-A copolymer and SEM images depicting surface morphology of $D$-A copolymer (inset $A$ ) at $\times 10.0 \mathrm{~K}$ and (inset $B$ ) at $\times 15.0 \mathrm{~K}$ (inset)

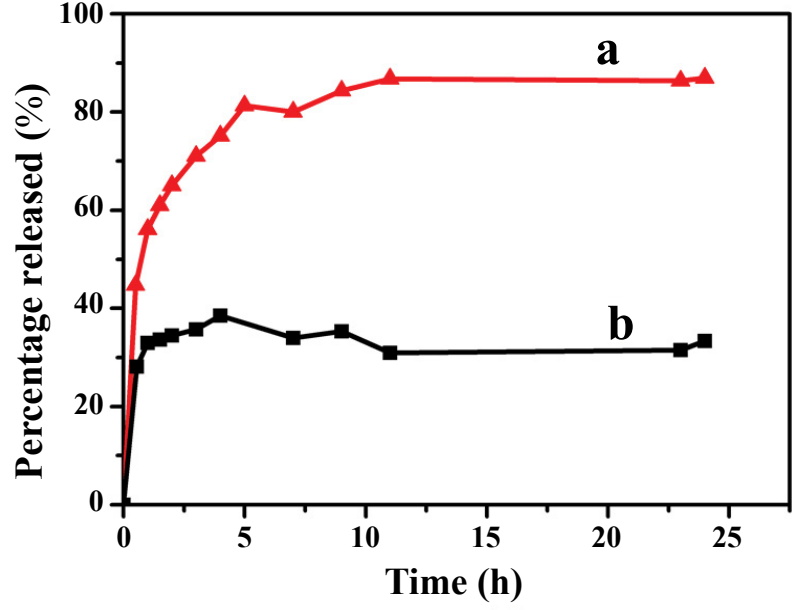

Fig. 2: IBU-release profile with time at two pH settings IBU-release behaviour from D-A copolymer in PBS solutions was measured at (a) pH 2.0 and (b) $\mathrm{pH} 7.4$

was negligible. The predominant hydrogen-bonding interactions via intra-molecular and inter-molecular interactions in the D-A copolymer forms a compact and ultra-coil conformation ${ }^{[29]}$, which can easily shrink to release the loaded IBU. In the alkaline solution (pH 7.4), the carboxyl groups inside the polymer were deprotonated as $-\mathrm{COO}^{-[5]}$, which increased the charge density on the polymer chains, weakened or even broken the hydrogen-bonding interactions, and thus enhanced the electrostatic repulsion ${ }^{[30]}$. The electrostatic repulsion among the $-\mathrm{COO}^{-}$groups of the D-A copolymer maintained its swelling status, leading to slow IBU-release and a small cumulated amount of IBU. These results evidently confirm that the D-A copolymer has an excellent $\mathrm{pH}$-sensitivity in physiological and biological environments due to its dissociable acid groups (-COOH). Therefore, it is necessary to further investigate the influence of the salt solution on the in vitro IBU-release performance from resultant D-A copolymer.

It has been reported that cation charge plays an important role in drug delivery. In the present work, the influences of the cation concentration on the release behaviours of I/D-P were determined at first. As can be seen from fig. 3A, the cumulative release decreased with the increasing of $\mathrm{NaCl}$ concentration from 0.0 to $0.2 \mathrm{M}$. The $24 \mathrm{~h}$ cumulative release reached to $\sim 85 \%$ in $1.0 \mathrm{M} \mathrm{HCl}, 73 \%$ in $0.1 \mathrm{M} \mathrm{NaCl}, 40 \%$ in $0.15 \mathrm{M}$ $\mathrm{NaCl}$, and $30 \%$ in $0.2 \mathrm{M} \mathrm{NaCl}$ (fig. 3A), respectively, in $24 \mathrm{~h}$. It can be explained that both D-A copolymer and IBU molecules have numerous hydroxide groups. The hydrogen-bonding interactions are one of the major bindings for the IBU adsorption on the D-A copolymer 
skeletons. The introduction of cations can significantly effect on the hydrogen-bonding between the copolymer and IBU and also among the copolymers molecules, which is favourable for the volume swelling of the copolymer. Therefore, IBU can be effectively confined inside the copolymer skeletons. In all, cations reduce the IBU-release performance of the copolymer by weaken the hydrogen-bonding between the copolymers and IBU.

The IBU-release profiles of the D-P copolymer in 0.1 $\mathrm{M} \mathrm{NaCl}$ and $0.1 \mathrm{M} \mathrm{CaCl}_{2}$ are depicted in fig. $3 \mathrm{~A}$. As can be seen, the balanced cumulative release reached $73 \%$ in the $\mathrm{NaCl}$ solution and $46 \%$ in the $\mathrm{CaCl}_{2}$ solution in $10 \mathrm{~h}$, indicating that the IBU-release was decreased with the increase of cation charge. It might be attributed to the stronger "ionic cross-linking density"[]] between $\mathrm{Ca}^{2+}$ and $-\mathrm{COO}^{-}$. While, $\mathrm{Na}^{+}$is surrounded with a large numbers of water molecules, which leads to a longer hydration radius, and thus weaker binding ability of $\mathrm{Na}^{+[31]}$.

Fig. 3B shows the effects of $\mathrm{Na}^{+}$concentration on the IBU-release performance of the D-A polymer in $1.2 \mathrm{M} \mathrm{NH}_{3} \cdot \mathrm{H}_{2} \mathrm{O}$ solutions. The cumulative release reached $76 \%$ in $1.2 \mathrm{M} \mathrm{NH}_{3} \cdot \mathrm{H}_{2} \mathrm{O}$ solutions in $24 \mathrm{~h}$. The additions of $0.05 \mathrm{M}, 0.1 \mathrm{M}$, and $0.2 \mathrm{M} \mathrm{NaCl}$ (fig. 3B) led to cumulative release amounts of 64,54 , and $43 \%$, respectively, indicating that the cumulative IBU-release from the copolymer was decreased with the increase of $\mathrm{Na}^{+}$concentration under alkali conditions. This is attributed to the weak hydrogen-bonding interactions between IBU and the copolymer caused by the high cation concentration.

The results presented above evidently demonstrate that the IBU-release rate of the D-A copolymer is decreased with the increase of ion concentration and ionic strength. The salt cation has a great influence on the drug release properties of the D-A copolymer and significantly reduces the controlled-release sensitivity. The swelling and shrinking properties of obtained copolymer are affected by its surface charge and particle distribution. Therefore, Zeta potential and particle distribution of the D-A copolymer was investigated in the following work. To further evaluate the release performance of the D-A copolymer, the kinetics of the IBU-release was determined at first by fitting the release profiles with the following theoretical models: Higuchi model ${ }^{[32]}, \mathrm{M}_{\mathrm{t}} /$ $\mathrm{M}_{\infty}=\mathrm{k}_{\mathrm{H}} \mathrm{t}^{0.5}$, where, $\mathrm{k}_{\mathrm{H}}$ is the Higuchi release constant; $M_{t}$ is the cumulative mass of IBU released at time t; and $\mathrm{M}_{\infty}$ is the total amount of the IBU loaded in the D-A copolymer. Korsmeyer-Peppas model ${ }^{[33]}: \mathrm{M}_{t} / \mathrm{M}_{\infty}$ $=\mathrm{kt}^{\mathrm{n}}$. Modified Korsmeyer-Peppas model ${ }^{[34]}, \mathrm{M}_{\mathrm{t}} / \mathrm{M}_{\infty}=$ $\mathrm{kt}^{\mathrm{n}}+\mathrm{C}$, where, $\mathrm{k}$ is a release constant; $\mathrm{n}$ is the diffusional exponent that varies with the solute mode of transport; and $\mathrm{C}$ is a constant that represents the initial burst effect. Based on these models, the drug release from polymer in a solvent in thermodynamic equilibrium is Fickian if $\mathrm{n}<0.43^{[35]}$ and is non-Fickian or anomalous if $0.43<\mathrm{n}<0.85$. Otherwise, the drug release is dominated by the corrosion of the polymer ${ }^{[36]}$.

The Eqns for each model and the kinetic parameters are listed in Table 1, and the fitted plots of the IBU-release profiles of D-A copolymer using Korsmeyer-Peppas model under different cation concentrations. As can be seen in Table 1, the squared correlation coefficient $\left(R^{2}\right)$ values obtained with the Higuchi model are in the range of 0.76-0.87, suggesting that the IBU-release profiles of D-A polymer do not fit this model well. Much higher $R^{2}$ values $(>0.99)$ were obtained with the Korsmeyer-

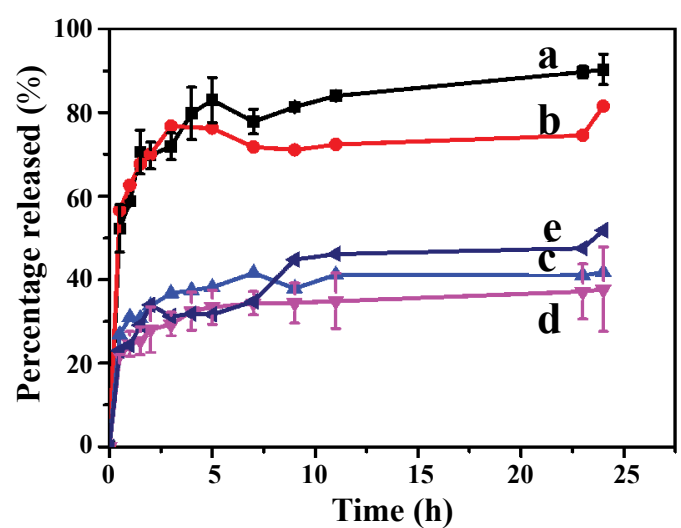

A.

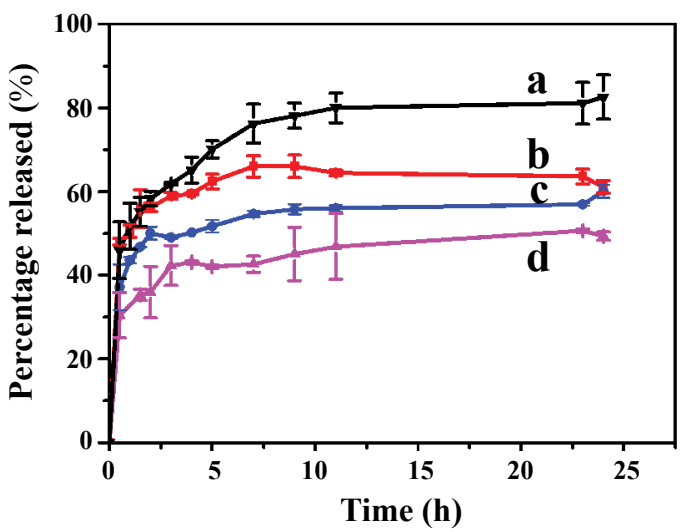

B.

Fig. 3: Influence of varying ionic strengths on the release of IBU from D-A copolymer at different $\mathrm{pH}$ values

A: (a) $1.0 \mathrm{M} \mathrm{HCl}$; (b) $0.1 \mathrm{M} \mathrm{NaCl+1.0M} \mathrm{HCl}$; (c) $0.15 \mathrm{M}$ $\mathrm{NaCl}+1.0 \mathrm{M} \mathrm{HCl}$; (d) $0.2 \mathrm{M} \mathrm{NaCl}+1.0 \mathrm{M} \mathrm{HCl}$; (e) $0.1 \mathrm{M}$ $\mathrm{CaCl}+1.0 \mathrm{M}$ HCl. B: (a) $1.2 \mathrm{M} \mathrm{NH}_{3} \cdot \mathrm{H}_{2} \mathrm{O}$, (b) $0.05 \mathrm{M} \mathrm{NaCl}+1.2$ $\mathrm{M} \mathrm{NH_{3 }} \cdot \mathrm{H}_{2} \mathrm{O}$; (c) $0.1 \mathrm{M} \mathrm{NaCl}+1.2 \mathrm{M} \mathrm{NH}_{3} \cdot \mathrm{H}_{2} \mathrm{O}$; and (d) $0.2 \mathrm{M}$ $\mathrm{NaCl}+1.2 \mathrm{M} \mathrm{NH}_{3} \cdot \mathrm{H}_{2} \mathrm{O}$ 
TABLE 1: THE MATHEMATICAL MODEL USED TO DESCRIBE DRUG RELEASE FROM D-A POLYMERS

\begin{tabular}{|c|c|c|c|c|c|}
\hline \multirow{3}{*}{ IBU-release media } & \multicolumn{2}{|c|}{ Higuchi } & \multicolumn{3}{|c|}{$\begin{array}{c}\text { Korsmeyer-Peppas } \\
\text { model }\end{array}$} \\
\hline & \multicolumn{2}{|c|}{$M_{t} / M=k_{u} t^{0.5}$} & \multicolumn{3}{|c|}{$M_{t} / M=k t^{n}$} \\
\hline & $K_{H}$ & $R^{2}$ & $k$ & $n$ & $R^{2}$ \\
\hline $\begin{array}{l}1.0 \mathrm{M} \mathrm{HCl} \\
\mathrm{pH}=2.0\end{array}$ & 0.37 & 0.8242 & - & - & - \\
\hline $\begin{array}{l}0.1 \mathrm{M} \mathrm{NaCl}+1.0 \mathrm{M} \mathrm{HCl} \\
\mathrm{pH}=2.0\end{array}$ & 0.43 & 0.8363 & 0.60 & 0.21 & 0.9942 \\
\hline $\begin{array}{l}0.15 \mathrm{M} \mathrm{NaCl}+1.0 \mathrm{M} \mathrm{HCl} \\
\mathrm{pH}=2.0\end{array}$ & 0.18 & 0.7931 & 0.31 & 0.13 & 0.9944 \\
\hline $\begin{array}{l}0.2 \mathrm{M} \mathrm{NaCl}+1.0 \mathrm{M} \mathrm{HCl} \\
\mathrm{pH}=2.0\end{array}$ & 0.15 & 0.8265 & 0.25 & 0.16 & 0.9921 \\
\hline $\begin{array}{l}0.1 \mathrm{M} \mathrm{CaCl}_{2}+1.0 \mathrm{M} \mathrm{HCl} \\
\mathrm{pH}=2.0\end{array}$ & 0.16 & 0.7677 & 0.26 & 0.16 & 0.9902 \\
\hline $\begin{array}{l}1.2 \mathrm{M} \mathrm{NH}_{3} \cdot \mathrm{H}_{2} \mathrm{O} \\
\mathrm{pH}=9.3\end{array}$ & 0.19 & 0.7965 & 0.52 & 0.17 & 0.9993 \\
\hline $\begin{array}{l}0.05 \mathrm{M} \mathrm{NaCl}+1.2 \mathrm{M} \\
\mathrm{NH}_{3} \cdot \mathrm{H}_{2} \mathrm{O} \\
\mathrm{pH}_{2}=9.3\end{array}$ & 0.30 & 0.8016 & 0.31 & 0.18 & 0.9965 \\
\hline $\begin{array}{l}0.1 \mathrm{M} \mathrm{NaCl}+1.2 \mathrm{M} \\
\mathrm{NH}_{3} \cdot \mathrm{H}_{2} \mathrm{O} \\
\mathrm{pH}^{2}=9.3\end{array}$ & 0.22 & 0.8155 & 0.29 & 0.15 & 0.9910 \\
\hline $\begin{array}{l}0.2 \mathrm{M} \mathrm{NaCl}+1.2 \mathrm{M} \\
\mathrm{NH}_{3} \cdot \mathrm{H}_{2} \mathrm{O} \\
\mathrm{pH}^{3}=9.3\end{array}$ & 0.21 & 0.8759 & 0.29 & 0.29 & 0.9911 \\
\hline
\end{tabular}

Peppas model, (except that in the $1.0 \mathrm{M} \mathrm{HCl}$ solution), indicating that it is suitable to elucidate the IBU-release kinetics. Particularly, $R^{2}=0.9994$ was obtained for the IBU-release rate of D-A copolymer in $1.0 \mathrm{M} \mathrm{HCl}$ in the first $1 \mathrm{~h}$ with the modified Korsmeyer-Peppas model for the pronounced burst effect.

The IBU-release kinetics also indicates that the rate constant $k$ decreases with the increase of cation charge. The release exponent $n$ is in the range of 0.13$0.29(<0.43)$, suggesting the diffusion-controlled release is by Fickian diffusion mechanism instead of corrosion. These results are in a good agreement with the previous reports of Hahn et al..$^{[37]}$ and Parfenyuk et $a l .{ }^{[38]}$. Evidently, two factors including salt cation and $\mathrm{pH}$ should be considered as the release forces. Cations can weaken the hydrogen-bonding interaction between dextran and PAA, especially in alkaline medium promoting the swelling volume of the copolymer and reducing the IBU-release rate. The enhanced electrostatic repulsions delay the IBU diffusion from D-A copolymer. In addition, thermodynamics equilibrium concentrations in the carrier and various release media are usually reached in $10 \mathrm{~h}$ (figs. 2 and 3 ). The effects of salt on the zeta potential of the D-A copolymer at different $\mathrm{pHs}$ are shown in fig. 4. As can be seen in fig. $4 \mathrm{~b}$, the D-A copolymer showed negative zeta potentials ranging from -13.5 to $-2.7(\mathrm{mV})$ in pure aqueous solutions with $\mathrm{pH}$ of 5.0-9.0, indicating that most carboxyl groups were deprotonated to - $\mathrm{COO}^{-}$. In this regard, the PAA easily leads to an overcharged surface and subsequently stronger electrostatic repulsion between - $\mathrm{COO}^{-}$groups, which cause higher negative zeta-potential ${ }^{[39]}$. The copolymer has an isoelectric point between $\mathrm{pH} 4.0$ and $\mathrm{pH} 5.0$ due to the $\mathrm{pKa}$ of PAA at $4.75^{[40]}$. Therefore, the D-A copolymer displayed a positive zeta potential at $\mathrm{pHs}$ below 4.0 due to the protonation of PAA in the acidic media. They interact with each other mainly through hydrogenbonding, which leads to positive zeta-potential and voluminous aggregation ${ }^{[41]}$. Moreover, the D-A copolymer also showed positive zeta potentials in the certain concentrations of $\mathrm{NaCl}$. However, the zeta potential profile in $0.1 \mathrm{M} \mathrm{NaCl}$ presented huge fluctuations at different $\mathrm{pH}$, and thus the obtained data were unreasonable and unrepeatable. Therefore, we chose $0.01 \mathrm{M} \mathrm{NaCl}$ to evaluate the effects of salt concentration on the zeta potential of the D-A copolymer. As depicted in fig. $4 \mathrm{a}$, the absolute value of the zeta potential in the $\mathrm{NaCl}$ solution is higher than that in pure aqueous solution, indicating that $\mathrm{Na}^{+}$ions can more significantly increase the surface charge of D-A copolymers due to hydrogen binding ability of the carboxylate groups. Consequently, the electrostatic repulsion force of copolymer is increased, leading to a decrease in its controlled-release ability. In addition, the zeta potential is positive in the alkaline solution due to the counter ions on the copolymer shielded by the bound ionic charges ${ }^{[31,32]}$.

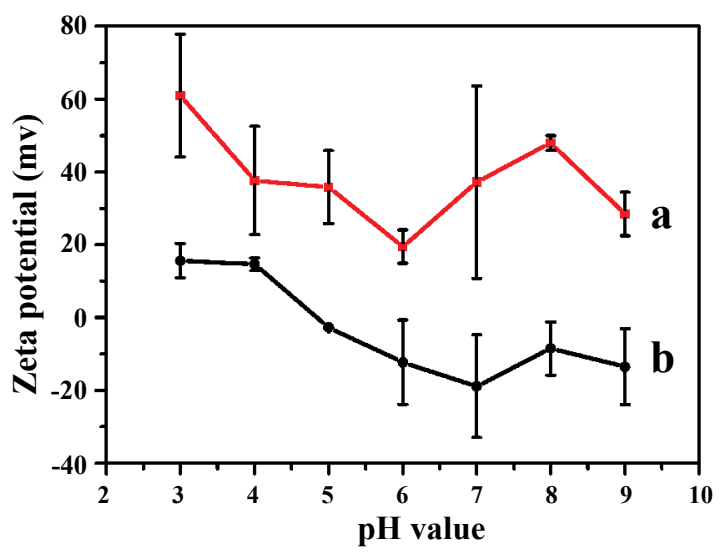

Fig. 4: Influence of varying $\mathrm{pH}$ on the Zeta potential of D-A copolymer

Zeta potential of D-A copolymer was measured at different $\mathrm{pH}$ values in (a) $0.01 \mathrm{M} \mathrm{NaCl}$ solution and (b) aqueous solution 
The particle size of the D-A copolymer varies with $\mathrm{Na}^{+}$concentrations and salt species in the $\mathrm{HCl}$ solution (fig. 5). As can be seen in fig. 5A, the D-A copolymer displayed a smaller size of $\sim 294 \mathrm{~nm}$ in $1.0 \mathrm{M} \mathrm{HCl}$. The average particle size gradually increased from 415 to $500 \mathrm{~nm}$, and $548 \mathrm{~nm}$ (statistical error, $3 \%$ ) as the ion concentration increased from 0.1 to $0.15 \mathrm{M}$, and $0.2 \mathrm{M}$, respectively, suggesting the structural transformation of the copolymer from shrinkage at low ion concentration to swelling at high ionic concentration. The average particle size of D-A copolymers in $0.1 \mathrm{M} \mathrm{CaCl}_{2}$ solution is $\sim 534 \mathrm{~nm}$, larger than that in $0.1 \mathrm{M} \mathrm{NaCl}$ (about $415 \mathrm{~nm}$ ), clearly indicating a strong influence of cation charge on the copolymer particle size. It has been reported that hydrogen-bonding and surface charge can impact on the particle size of the D-A copolymer ${ }^{[30]}$. The variation of copolymer particle size and volume at different $\mathrm{Na}^{+}$concentration and cation species is the key factor for its sensitivity as discussed above that the IBU-release rate of the D-A copolymer decreased with the increasing of $\mathrm{NaCl}$ concentration (fig. 3A). The increment in the expansion of the copolymer volume at high $\mathrm{NaCl}$ concentrations impacts adversely on the controlled-release. Therefore, it is inferred here that the cation charge could also play an important role in the drug-release performance of the D-A copolymer in an acidic medium.

As shown in fig. 5B, the particle size of the D-A copolymer increased from 453 to $573 \mathrm{~nm}$ (statistical error, $\sim 3 \%$ ) as the $\mathrm{NH}_{3} \cdot \mathrm{H}_{2} \mathrm{O}$ concentration increased to $0.2 \mathrm{M}$. This indicates that cations have a remarkable influence on the drug release in alkaline solution, consisting with the results discussed above (fig. 3B).

Based on above discussions, we propose a possible mechanism as follows: the high ion concentration of the releasing solution could easily cause the enhancement of the surface charge of the D-A copolymer, and increasing the particle size, obvious leading to the lower IBU-release rate, particularly, in acidic aqueous solutions than that in alkaline medium. In all, the high cation concentration and ionic strength could be helpful to increase particle size of the D-A copolymer, leading to its poor drug-release performance.

In addition, according to the electrolyte composition of GI fluids deriving from literature ${ }^{[42,43]}$, it is unlikely that the low ionic strengths of $0.01-0.16 \mathrm{mEq} / 1$ for gastric and $0.070-0.166 \mathrm{meg} / \mathrm{l}$ for intestinal fluids would undergo in vivo influences on the $\mathrm{pH}$-sensitive release performances using D-A copolymer as a drug carrier. In

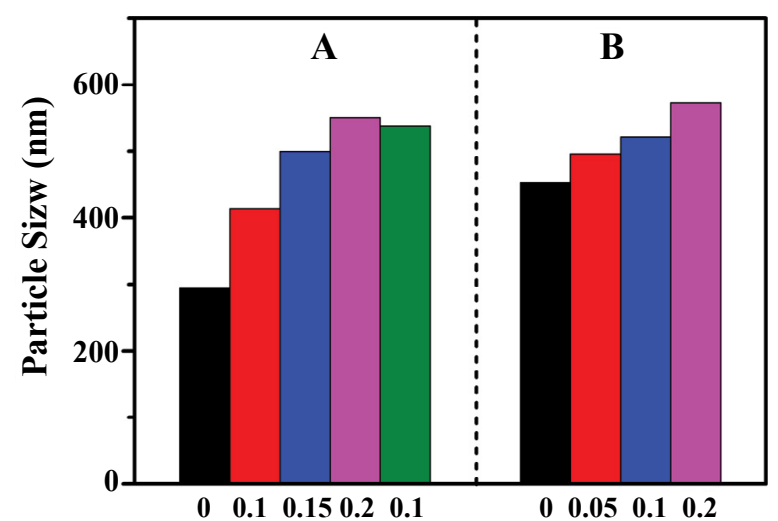

Fig. 5: Influence of $\mathrm{pH}$ and ionic concentrations on the particle size of D-A copolymer

Particle size of D-A copolymer at (A) pH 2 (1.0 M HCI) solution containing various $\mathrm{Na}^{+}$amounts and $0.1 \mathrm{M} \mathrm{CaCl}_{2}$ and (B) $\mathrm{pH}$ 9.3 (1.2 $\left.\mathrm{M} \mathrm{NH} \cdot \mathrm{H}_{2} \mathrm{O}\right)$ solution with different $\mathrm{Na}^{+}$concentrations. — $0 \mathrm{NaCl}$; $0.1 \mathrm{M} \mathrm{NaCl}$; $0.15 \mathrm{M} \mathrm{NaCl}$; $0.2 \mathrm{M} \mathrm{NaCl} ; \approx 0.1$ $\mathrm{M} \mathrm{CaCl}_{2}$

this way, the obtained D-A copolymers should be a good candidate as a drug carrier for potential drug delivery applications. But, the salt cationic concentration (up to $0.2 \mathrm{M} / \mathrm{l})$ and charge $\left(\mathrm{Na}^{+}\right.$or $\left.\mathrm{Ca}^{2+}\right)$ of the solution used in this study exceeded the physiological ionic strength conditions in the human GI tract, which have a great impact on its drug release properties and significantly reduce the controlled-release sensitivity, as shown in figs. 3-5.

The effects of cations in the release solution on the IBU-release performance of D-A copolymers were evaluated in different solutions with different $\mathrm{pH}$ and containing various concentrations of $\mathrm{Na}^{+}$or $\mathrm{Ca}^{2+}$ cations. The results indicate that the copolymer was $\mathrm{pH}$-sensitive and showed a fast IBU release in low $\mathrm{pH}$ solutions and slow IBU release in high $\mathrm{pH}$ solutions. Increasing the ionic concentration of the release solutions from 0.05 to $0.20 \mathrm{M}$ resulted in a decrease in the cumulative release rate. The tendency to decline is more pronounced in an acidic solution than that in an alkaline medium.

The IBU cumulative release rate of the D-A copolymer in the $\mathrm{Ca}^{2+}$ solution is significantly lower than that in the $\mathrm{Na}^{+}$solution, indicating that ionic strength can also impact on the IBU-release performance of the D-A copolymer. The ion concentration and ionic strength effect on the zeta potential and particle distribution of the D-A polymer by changing the hydrogen-bonding, electrostatic interaction, and surface charge, which further impacts on its swollen/shrunken volume and IBU-release performance. In summary, the cations in the release solution can significantly influence on the drug-release profile of the D-A copolymer. 


\section{Acknowledgements:}

This project was supported by the National Natural Science Foundation of China (21576005), and the Beijing Municipal Natural Science Foundation (2152005).

\section{Conflicts of interest:}

There are no conflicts of interest.

\section{Financial support and sponsorship:}

Nil.

\section{REFERENCES}

1. Dittgen M, Durrani M, Lehmann K. Acrylic polymers-A review of pharmaceutical applications. STP Pharma Sci 1997;7:403-37.

2. Quintero SMM, Ponce FRV, Cremona M, Triques ALC, d'Almeida AR, Braga AMB. Swelling and morphological properties of poly(vinyl alcohol) (PVA) and poly(acrylic acid) (PAA) hydrogels in solution with high salt concentration. Polymer 2010;5:1953-8.

3. Abd El-Rehim HA, Hegazy EA, Khalil FH, Hamed NA. Radiation preparation of drug carriers based polyacrylic acid (PAAc) using poly(vinyl pyrrolidone) (PVP) as a template polymer. Nucl Instrum Methods Phys Res B 2007;B254:105-12.

4. Bury K, Neugebauer D. Novel self-assembly graft copolymers as carriers for antiinflammatory drug delivery. Int $\mathrm{J}$ Pharm 2014;460:150-57.

5. Wilson CG, Washington N, Greaves JL, Kamali F, Rees JA, Semplk AK, et al. Bimodal release of ibuprofen in a sustainedrelease formulation-a scintigraphic and pharmacokinetic open study in healthy-volunteers under different conditions of foodintake. Int J Pharm 1989;50:155-61.

6. Charman WN, Porter CJH, Mithani SD, Ressman JB. Physicochemical and physiological mechanisms for the effects of food on drug absorption: The Role of lipids and $\mathrm{pH}$. J Pharm Sci 1997;86:269-82.

7. Sasa B, Odon P, Stane S, Julijana K. Analysis of surface properties of cellulose ethers and drug release from their matrix tablets. Eur J Pharm Sci 2006;27:375-83.

8. Lapidus H, Lordi NG. Drug release from compressed hydrophilic matrices. J Pharm Sci 1968;57:1292-301.

9. Mitchel K, Ford JL, Armstrong DJ, Elliott PNC, Rostron $\mathrm{C}$, Hogan JE. The influence of additives on the cloud point, disintegration and dissolution of hydroxypropyl methylcellulose gels and matrix tablets. Int $\mathrm{J}$ Pharm 1990;66:233-42.

10. Johnson JL, Holinej J, Williams MD. Influence of ionic strength on matrix integrity and drug release from hydroxypropyl cellulose compacts. Int J Pharm 1993;90:151-59.

11. Fu Q, Rao GVR, Ista LK, Wu Y, Andrzejewski BP, Sklar LA, et al. Control of molecular transport through stimuli-responsive ordered mesoporous materials. Adv Mater 2003;15:1262-66.

12. Awasthi S, Singhal R. A mathematical study on effect of 2-hydroxyl ethyl acrylate on controlled drug diffusion from smart hydrogels based on poly(acrylamide-co-hydroxy ethyl acrylate-co-acrylic acid). J Macromol Sci Pure Appl Chem 2012;49:397-413.
13. Bai SY, Zhang H, Sun JH, Han J, Guo YY. Preparation and pHresponsive performance of silane-modified poly(methylacrylic acid). J Appl Polym Sci 2014;131:40403-10.

14. Thoren L. The dextrans-clinical data. Dev Biol Stand 1981;48:157-67.

15. Cristallini C, Barbani N, Giusti P, Lazzeri L, Cascone MG, Ciardelli G. Polymerisation onto biological templates, a new way to obtain bioartificial polymeric materials. Macromol Chem Phys 2001;202:2104-13.

16. Chauvierre C, Labarre D, Couvreur P, Vauthier C. Radical Emulsion polymerization of alkylcyanoacrylates initiated by the redox system dextran-cerium(IV) under acidic aqueous conditions. Macromolecules 2003;36:6018-27.

17. Heidrick GW, Pippitt Jr CH, Morgan MA, Thurnau GR. Efficacy of intraperitoneal sodium carboxymethyl cellulose in preventing postoperative adhesion formation. J Reprod Med 1994;39;575-8.

18. Tang MH, Dou HJ, Sun K. One-step synthesis of dextranbased stable nanoparticles assisted by self-assembly. Polymer 2006;47:728-34.

19. Zhang RS, Tang MG, Bowyer A, Eisenthal R, Hubble J. A novel $\mathrm{pH}$ and ionic-strength-sensitive carboxymethyl dextran hydrogel. Biomaterials 2005;26:4677-683.

20. Heidrick GW, Pippitt CH, Morgan MA, Thurnau GR. Efficacy of intraperitoneal sodium carboxymethylcellulose in preventing postoperative adhesion formation. J Reprod Med 1994;39:575-8.

21. Guo YY, Sun JH, Bai SY, Zhang YN, Wu X. Preparation of pH-sensitive Dextran-Poly (acrylic acid) copolymer and its application as a controlled ibuprofen delivery. Int J Polym Mater Polym Biomater 2017;66(17):900-06.

22. Cai X, Wang N, Lin X. Chemo-enzymatic synthesis of optically active polymeric prodrug of naproxen, ketoprofen and ibuprofen. Polymer 2006;47:6491-95.

23. Chen HB, Wen T, Chang XL, Yang YJ, Yang XL. Preparation of ibuprofen microemulsion and its transdermal absorption. Chin Pharm J 2004;39:43-5.

24. Peniche C, Arguelles-Monal W, Davidenko N, Sastre R, Gallardo A, San Roman J. A novel mucoadhesive polymer prepared by template polymerization of acrylic acid in the presence of chitosan. Biomaterials 1999;20:1869-78.

25. Barbani N, Bertoni F, Ciardelli G, Cristallini C, Silvestri D, Coluccio ML, et al. Bioartificial materials based on blends of dextranand poly(vinyl alcohol-co-acrylic acid). Eur Polym J 2005;41:3004-10.

26. Tang HY, Guo J, Sun Y, Chang BS, Ren QG, Yang WL. Facile synthesis of $\mathrm{pH}$ sensitive polymer-coated mesoporous silica nanoparticles and their application in drug delivery. Int $\mathrm{J}$ Pharm 2011;42:388-96.

27. Shukla R, Goyal A. A novel dextran from pediococcus pentosaceus CRAG3 isolated from fermented cucumber with anti-cancer properties. Int J Biol Macromol 2011;62:352-57.

28. Ahn JS, Choi HK, Cho CS. A novel mucoadhesive polymer prepared by template polymerization of acrylic acid in the presence of chitosan. Biomaterials 2001;22:923-28.

29. Dou HJ, Sun K, Yang WH. The self-assembly of hydroxypropylcellulose and carboxy-ended surfactants to multi-morphological nanoparticles. Macromol Chem Phys 2006;207:1899-904.

30. Hu Y, Chen Y, Chen Q, Zhang LY, Jiang XQ, Yang CZ. Synthesis and stimuli-responsive properties of chitosan/poly(acrylic acid) hollow nanospheres. Polymer 2005;46:12703-10. 
31. Sadeghi M, Hosseinzadeh H. Synthesis and super swelling behaviour of carboxymethylcellulose-poly(sodium acrylate-coacrylamide) hydrogel. J Appl Polym Sci 2008;108:1142-51.

32. Higuchi T. Mechanism of sustained action medication, theoretical analysis of rate of release of solid drugs dispersed in solid matrices. J Pharm Sci 1963;52:1145-49.

33. Korsemeyer RW, Gurny R, Doelker E, Pierre NB, Peppas A. Mechanisms of solute release from porous hydrophilic polymers. Int J Pharm 1983;15:25-35.

34. Kim H, Fassihi R. Application of a binary polymer system in drug release rate modulation.1. Characterization of release mechanism. J Pharm Sci 1997;86:316-22.

35. Katime I, Valderruten N, Quintana JR. Controlled release of aminophylline from poly (N-isopropylacrylamide-co-itaconic acid) hydrogels. Polym Int 2001;50:869-79.

36. Lynch I, Dawson KA. Release of model compounds from "plum-pudding"-type gels composed of microgel particles randomly dispersed in a gel matrix. J Phys Chem B 2004;108:10893-98.

37. Hahn A, Brandes G, Wagener P, Barcikowski S. Metal ion release kinetics from nanoparticle silicone composites. J Control Release 2011;154:164-70.

38. Parfenyuk EV, Dolinina ES. Design of silica carrier for controlled release of molsidomine: Effect of preparation methods of silica matrixes and their composites with molsidomine on the drug release kinetics in vitro. Eur J Pharm Biopharm 2014;88:1038-45.

39. Joksimovic R, Prevost S, Schweins R, Appavou MS, Gradzielski M. Interactions of silica nanoparticles with poly(ethylene oxide) and poly(acrylic acid): Effect of the polymer molecular weight and of the surface charge. J Colloid Interface Sci 2013;394:85-93.

40. Ahn JS, Choi HK, Lee KH, Nahm JH, Cho CS. Novel mucoadhesive polymer prepared by template polymerization of acrylic acid in the presence of silk sericin. J Appl Polym Sci 2001;80:274-80.

41. Arias JL, Lopez-Viota M. Stability of fenbendazole suspensions for veterinary use Correlation between zeta potential and sedimentation. Eur J Biochem 2008;34:257-62.

42. Collins RD. Illustrated Manual of Fluid and Electrolyte Disorders. 2nd ed. Philadelphia: Lippincott; 1983. p. 190.

43. Goldberger E, Brensilver JM. A Primer of Water, Electrolyte, and Acid-Base Syndromes, 7th ed. Philadelphia: Lea \& Febiger; 1986. p. 74. 